\title{
De onderwijsvisitatie geneeskunde van de Vlaamse universiteiten in 2005
}

\author{
B. Meyboom-de Jong, J.C.M. Metz
}

\section{Samenvatting}

In 2005 is aan de zes Vlaamse universiteiten die een opleiding geneeskunde kennen de kwaliteit van het onderwijs geëvalueerd en de huisartsenopleiding. De visitatieprocedure is vergelijkbaar met die in Nederland. Het visitatierapport is via de website van de Vlaamse Interuniversitaire Raad (http://www.vlir.be/vlir/02thema\%27s/03kz/0303tweede-ronde.htm) te raadplegen. Vlaanderen heeft voor haar zes miljoen inwoners vier volledige opleidingen geneeskunde, en twee bacheloropleidingen in Kortrijk en Hasselt. De opleidingen en de faculteiten verschillen sterk van elkaar in grootte, onderwijsvoorwaarden en onderwijsklimaat.

De conclusie van de visitatiecommissie luidde, kort samengevat, dat het medisch onderwijs in Vlaanderen op dit moment kwalitatief van hoog niveau is en aan de gestelde eisen voldoet. Dit is mede het gevolg van alle verbeteringen die sinds de vorige visitatie in 1997 zijn doorgevoerd.

In Vlaanderen is de bachelor-masterstructuur ingevoerd, maar de opleiding geneeskunde duurt er nog zeven jaren. In tegenstelling tot Nederland kent Vlaanderen een naadloze aansluiting tussen basisopleiding en vervolgopleiding.

Voor getalenteerde en gemotiveerde studenten zou een gecombineerde opleiding tot arts en wetenschappelijk onderzoeker gecreëerd moeten worden, de zogenaamde MD/PhD-opleiding.

De ontwikkelingen op IT-gebied waren ver voortgeschreden, maar de opdrachten aan de studenten waren nog vaak gebaseerd op lesmateriaal dat door de docent uitgezocht en kant en klaar in klappers werd aangeleverd. De verandering van een 'authority based' curriculum naar een 'evidence based' curriculum zou systematischer kunnen worden doorgevoerd. Hiertoe zouden de onderwijscommissies meer invloed en macht moeten krijgen en de autonomie van de individuele docent meer beknot moeten worden.

Over de interessante en succesvolle ontwikkelingsprojecten op het gebied van het onderwijs was nauwelijks gepubliceerd.

De visitatiecommissie adviseert om vast te stellen of de eindtermen werkelijk bereikt worden door een aantal jaren de Maastrichtse voortgangstoets af te nemen. (Meyboom-de Jong B, Metz JCM. De onderwijsvisitatie geneeskunde van de Vlaamse universiteiten in 2005. Tijdschrift voor Medisch Onderwijs 2006;25(3):111-116.)

\section{Inleiding}

In 2005 is aan de zes Vlaamse universiteiten die een opleiding geneeskunde kennen de kwaliteit van het onderwijs geëvalueerd door een visitatiecommissie van 'buitenlanders': drie Nederlandse en twee Vlaamse experts die 30-40 jaar geleden naar de Verenigde Staten respectievelijk Duitsland zijn geëmigreerd, een secretaris van de Vlaamse Interuniversitaire Raad en twee Vlaamse studenten. Tevens werd de huisartsenopleiding geëvalueerd. Het eerste jaar van de driejarige specialisatie tot huisarts valt, als zevende jaar van de artsopleiding, onder de verantwoordelijkheid van de faculteiten, terwijl de laatste twee jaren van de huisartsenopleiding centraal door het Interuniversitair Cen- 
trum HuisartsenOpleiding (ICHO) worden georganiseerd.

De visitatieprocedure is vergelijkbaar met die in Nederland. De visitatiecommissie baseert haar oordeel op de door de faculteiten geschreven zelfevaluatie met bijlagen, de tijdens de visitatiebezoeken gevoerde gesprekken met alle geledingen van de universiteit, de rondleiding langs practicumruimten, bibliotheekvoorzieningen en materiaal (cursusboeken, handleidingen, e.d.) dat tijdens de bezoeken ter inzage lag.

Het rapport, dat ook op de website staat, bestaat uit het referentiekader dat de visitatiecommissie gehanteerd heeft, een hoofdstuk over de opleidingen in vergelijkend perspectief, een beoordelingsrapport per faculteit met concrete aanbevelingen en een algemene beschouwing waarin de commissie haar opvattingen weergeeft over aspecten die het belang van de individuele faculteit overschrijden. ${ }^{1-2}$

Vlaanderen heeft voor haar zes miljoen inwoners vier volledige opleidingen geneeskunde, twee aan relatief grote faculteiten in Gent en Leuven en twee aan relatief kleine faculteiten in Antwerpen en de Vrije Universiteit te Brussel. Daarnaast zijn er twee bacheloropleidingen in Kortrijk en Hasselt. De opleidingen en de faculteiten waar zij gevestigd zijn, verschillen sterk van elkaar in grootte, onderwijsvoorwaarden en onderwijsklimaat.

De conclusie van de commissie luidde, kort samengevat, dat het medisch onderwijs in Vlaanderen op dit moment kwalitatief van hoog niveau is en aan de gestelde eisen voldoet. Dit is mede het gevolg van alle verbeteringen die sinds de vorige visitatie in 1997 zijn doorgevoerd.

\section{Vlaams toelatingsexamen}

Door het sinds 1998 verplichte Vlaamse toelatingsexamen zijn de kwaliteit en de homogeniteit van de eerstejaars studen- ten geneeskunde en daarmee de slaagcijfers sterk verbeterd. Het toelatingsexamen heeft er ook in geresulteerd dat het eerste jaar niet langer een selectiejaar is waarin geblokt moet worden op basisvakken als plantkunde, dierkunde, scheikunde en natuurkunde. $\mathrm{Nu}$ kan in het eerste jaar de studie geneeskunde direct een aanvang nemen. De meeste basisvakken zijn dan ook gemedicaliseerd, d.w.z. op het inzicht en de toepassing in de geneeskunde toegesneden.

Een gevolg van de invoering van het toelatingsexamen was ook dat het aantal (eerstejaars) studenten drastisch daalde, zij het niet voor alle opleidingen even sterk. Het aantal ingeschreven studenten correleert niet rechtstreeks met de kwaliteit van het gegeven onderwijs. Zelfs de twee kleine faculteiten en de twee bacheloropleidingen zijn gekenmerkt door een kleinschalige onderwijssituatie waarin bepaalde jaargroepen de grootte van een schoolklas hebben. Zelfs de twee 'grote' faculteiten hebben studentenaantallen die in veel West-Europese landen als middelgroot zouden gelden. Vlaanderen heeft wat betreft de omvang van het personeelsbestand een unieke positie in Europa: relatief veel stafleden per student.

Naast de invoering van het verplichte toelatingsexamen zijn er nog twee besluiten van de Vlaamse overheid van belang voor het medisch onderwijs. Van de afstuderende studenten dient $43 \%$ tot huisarts en $57 \%$ tot specialist te worden opgeleid. Vaak wordt dit percentage van $43 \%$ niet gehaald, omdat de opleidingen weinig huisartsgeneeskundig onderwijs en weinig huisartsgeneeskundige stages in hun bachelor- en masteropleiding aanbieden. Studenten hebben daardoor veel minder kennis over en contact met de huisartspraktijk dan met de specialismen in het ziekenhuis. Het derde besluit betreft de contingentering, waardoor het aantal 
Vlaamse specialisten dat mag worden opgeleid, is beperkt.

\section{Studie geneeskunde zeven jaar}

In Vlaanderen worden de Europese richtlijnen uitgevoerd, waaronder de invoering van de bachelor-masterstructuur. Daarom heeft de commissie zich verbaasd over het feit dat in Vlaanderen als enig land in Europa de opleiding geneeskunde nog zeven jaren duurt. In dit zevende jaar vinden stages plaats waarin de selectie voor de vervolgopleiding plaatsvindt. De studenten klagen dat zij in het zevende jaar, vooral in de pre-specialistenopleiding, soms als werkkracht worden ingezet. Deze periode in het zevende jaar telt niet mee voor de klinische specialistenopleiding, terwijl dat voor diegenen die de specialisatie huisartsgeneeskunde kiezen wel het geval is. Het feit dat het zevende jaar voor de ene specialisatie wel en voor de andere niet meetelt, acht de commissie oneerlijk. Volgens de commissie zou de studie tot arts ook in Vlaanderen na zes jaar afgerond kunnen zijn.

In tegenstelling tot Nederland kent Vlaanderen een naadloze aansluiting tussen basisopleiding en vervolgopleiding. ${ }^{3}$ De schakelfunctie van het zevende jaar, waarin specialisten-in-opleiding geselecteerd worden zodat zij direct na het artsexamen met hun vervolgopleiding kunnen beginnen, zou in de nieuwe structuur dan ook behouden moeten blijven. Huisartsen kunnen zich al aan het begin van het zevende jaar, dus nog vóór het artsexamen, als huisarts gaan specialiseren. Halverwege het zevende jaar komt daar dan nog een aantal huisartsen in spe bij, die geen opleidingsplaats tot specialist hebben kunnen bemachtigen. Deze groep wordt op $20 \%$ geschat. Wachten heeft in Vlaanderen geen zin, omdat na een jaar weer een nieuw cohort zevendejaars de opleidingsplaatsen voor huisarts en specialist vullen.
Het gevolg van deze naadloze aansluiting is dat er jonge huisartsen en specialisten - een neurochirurg van 29 en huisartsen van 28 jaar - zijn die in geen ander land worden aangetroffen.

\section{Vlaams raamplan}

Door alle bij de visitatie betrokken universiteiten zijn doelstellingen (eindtermen, competenties) voor de artsopleiding beschreven, waarin veel gemeenschappelijke elementen worden aangetroffen. De visitatiecommissie acht de tijd rijp voor de totstandkoming van een gemeenschappelijk, door alle Vlaamse medische faculteiten onderschreven raamplan, dat alle opleidingen bij de constructie van hun curriculum als leidraad nemen.

\section{(Ontbrekende) samenwerking}

De medische faculteiten in Vlaanderen worden gekenmerkt door intensieve samenwerking met buitenlandse wetenschappers en wetenschappelijke instellingen. Nationaal is van samenwerking en uitwisseling echter nauwelijks sprake. Binnen Vlaanderen kan de situatie kort samengevat worden met 'het bestaan van schotten en concurrentie'. Een intensivering van de samenwerking tussen de universiteiten/faculteiten geneeskunde is noodzakelijk. Ten eerste om economische redenen: middelen kunnen dan veel doelmatiger worden ingezet. Ten tweede, omdat ook in Vlaanderen excellente topinstituten met een beperkte focus ontstaan ten behoeve van internationaal wetenschappelijk onderzoek. In de toekomst zullen de medische faculteiten evolueren van instellingen met een volledig aanbod tot instellingen met excellente zwaartepunten, die de ontbrekende onderdelen door samenwerkingsverbanden met andere wetenschappelijke en klinische instellingen zullen completeren. 
In het algemeen is sprake van een goede samenwerking tussen de medische faculteiten en de universitaire ziekenhuizen, hoewel van integratie zoals in de Nederlandse universitaire centra (nog) geen sprake is.

Ook de samenwerking met de perifere, bij de opleiding betrokken ziekenhuizen, waar veel klinische stages plaatsvinden, is goed. De honorering van deze klinische stages kan nog verbeterd worden, zodat aan inhoud, begeleiding en beoordeling van het in de periferie gegeven onderwijs eisen kunnen worden gesteld.

Praktische stages waarin studenten hun theoretische kennis aan de praktijk kunnen toetsen, worden meer en meer ingevoerd. Het onderwijs in medisch-technische en communicatieve vaardigheden is uitgebreid en op veel plaatsen vanaf het begin van het eerste jaar ingevoerd.

\section{Wetenschappelijke vorming en IT}

Overal werd aandacht besteed aan wetenschappelijke vorming, waarvan de commissie excellente voorbeelden heeft gezien. Het advies luidde om, mede in het kader van de flexibilisering, voor getalenteerde en gemotiveerde studenten een gecombineerde opleiding tot arts en wetenschappelijk onderzoeker te creëren, de zogenaamde $\mathrm{MD} / \mathrm{PhD}$-opleiding die in de Verenigde Staten uitvoerig geëvalueerd is en als gecombineerde opleiding zowel tot dokter als tot doctor opleidt.

De ontwikkelingen op IT-gebied waren ver voortgeschreden. Eigenlijk hadden alle studenten overal aansluiting op het universitaire web, zodat ze gemakkelijk literatuur konden vinden en raadplegen, ook vanuit hun 'kot'. Op dit terrein was het onderwijs volop in ontwikkeling. Zo hebben wij een examen radiologie bijgewoond waar ter plekke de vragen uit een grote database gekozen en digitaal beantwoord werden. Ondanks deze mo- gelijkheden werden de opdrachten aan de studenten nog vaak gebaseerd op lesmateriaal dat door de docent uitgezocht en kant en klaar in klappers werd aangeleverd. De studenten waren erg enthousiast over de kant en klare klappers, omdat die goed weergeven wat de docenten willen horen op het examen. Zij krijgen een hoog cijfer als ze de vaak detaillistische 'bijvragen' van de docent goed beantwoorden. De verandering die reeds is ingezet van een 'authority based' curriculum naar een 'evidence based' curriculum zou ook op dit gebied nog systematischer kunnen worden doorgevoerd.

\section{Aansturing onderwijs}

Formeel is de aansturing van het onderwijs via de verschillende onderwijscommissies meestal goed geregeld. Het ontbreekt deze commissies veelal aan voldoende slagvaardigheid en 'macht' om herzieningen van het onderwijs gedaan te krijgen. Voor een deel is dit het gevolg van de relatieve kleinschaligheid van de instellingen en de angst individuele docenten voor het hoofd te stoten. Daarnaast wordt dit veroorzaakt door de verschillen tussen de verschillende werkgevers: universiteit en faculteit enerzijds versus het ziekenhuis anderzijds. In een geïntegreerd curriculum dat gericht is op professionele deskundigheid, is de autonomie van de docent vanzelfsprekend ondergeschikt aan inhoudelijke vereisten die door de opleiding en curriculumverantwoordelijken worden gesteld.

Het keuzeonderwijs is veelal te weinig ontwikkeld en ook dit heeft te maken met de relatieve onmacht om herzieningen - en daarmee beknotting van de onderwijsuren van docenten - te bewerkstellingen. Een meer centrale verantwoordelijkheid voor de opbouw en sturing van het curriculum is gewenst. Een centrale groep van docenten en onderwijskundigen met vertegenwoordigers van de facultaire overheid kan 
betere garanties scheppen voor de gewenste integratie van de opleidingsonderdelen, zowel horizontaal tussen de verschillende onderdelen in een studiejaar als verticaal tussen de opeenvolgende studiejaren. Door een dergelijke centrale groep verantwoordelijk te maken voor het onderwijs, kan de traditionele 'autonomie van de docent' beperkt worden. De opbouw van het curriculum kan daardoor evenwichtiger worden en door het planmatig aanbrengen van een geleidelijk toenemende complexiteit en moeilijkheidsgraad leiden tot een beter studeerbaar programma.

Bij de toetsing worden nog te vaak toetsvormen gebruikt die voor de te testen leerdoelen niet geëigend zijn, zoals het mondelinge examen met schriftelijke voorbereiding. Dat laatste speelt op verschillende plaatsen nog steeds een overheersende rol, ofschoon de betrouwbaarheid van het mondelinge examen algemeen als laag wordt erkend. De alternatieve oplossing die soms toegepast wordt, namelijk het afzonderen van examinandi en hen achtereenvolgens laten antwoorden op identieke vragen, leidt tot onaanvaardbaar lange wachttijden voor de later ondervraagde studenten. De commissie pleit voor de ontwikkeling en implementatie van een opleidingsbreed toetsingsbeleid, waarbij regels en bevoegdheden worden ontwikkeld voor controle op de relevantie en kwaliteit van de examenvragen. Kwaliteitszorg van de toetsing en bewaking van de validiteit en de betrouwbaarheid van iedere toets, zowel schriftelijk als mondeling, gelden daarbij als hoogste prioriteit.

\section{Onderzoek van onderwijs}

Tijdens de bezoeken heeft de commissie vele interessante en succesvolle ontwikkelingsprojecten op het gebied van het onderwijs gezien. Slechts over een minderheid was gepubliceerd, zodat anderen in binnen- en buitenland van die resultaten niet kunnen profiteren.

\section{Behaalde eindtermen}

De visitatiecommissie is van mening dat er nog geen sluitend systeem bestaat waarmee kan worden vastgesteld of de eindtermen werkelijk bereikt worden. $\mathrm{Zij}$ is van oordeel dat op dit gebied de ontwikkelingen nog in de kinderschoenen staan. Het enige instrument op dit gebied dat zij heeft ontmoet, is de Maastrichtse voortgangstoets. ${ }^{4}$ Aan de Universiteit van Gent werden de gevolgen van de fundamentele curriculumvernieuwing nagegaan door de resultaten op deze voortgangstoets bij studenten van het oude en het vernieuwde curriculum te vergelijken. De commissie was zeer gecharmeerd van dit initiatief en acht deze aanpak veelbelovend. Zij wil de Vlaamse faculteiten in overweging geven jaarlijks eenmaal door alle studenten geneeskunde de Maastrichtse voortgangtoets te laten invullen. Om vertekening door een eenmalige invulling tegen te gaan, zou de Maastrichtse voortgangstoets gedurende een aantal jaren toegepast kunnen worden, bijvoorbeeld in de vier jaren voor de volgende visitatie. Op die manier raken de studenten gewend aan deze wijze van toetsen en kunnen na het overwinnen van startproblemen de resultaten van de verschillende opleidingen worden vergeleken.

\section{Welke faculteit kiest de commissie}

Nadat de commissie op zes plaatsen het onderwijs had geëvalueerd en met grote eenstemmigheid haar conclusies had geformuleerd, bleek het niet mogelijk aan het eind van dit proces consensus te bereiken over de faculteit waar de commissieleden de voorkeur aan zouden geven als zij weer voor de keus stonden. Die variabiliteit is een groot goed. Tijdens de bezoeken werden zeer enthousiaste studenten 
ontmoet die hard werkten en tijd vonden om zich naast hun studie voor allerlei andere zaken binnen en buiten de studie te engageren. Dat beoordeelde de commissie positief.

\section{Literatuur}

1. Vlaamse Interuniversitaire Raad. De onderwijsvisitatie geneeskunde. Brussel: VLIR; 2005.

2. De visitatie geneeskunde (2005) [rapport op internet]. Vlaamse Interuniversitaire Raad [geciteerd 9 mei 2006]. Beschikbaar op: http://www.vlir. be/02thema/03kz/03tweederonde/59.htmwww. vlir.be/vlir/02thema $\% 27 \mathrm{~s} / 03 \mathrm{kz} / 0303$ tweede-ronde. htm.

3. Meyboom-de Jong B. Schmit Jongbloed LJ, Willemse MC, editors. De arts van straks. Een nieuw medisch opleidingscontinuum. Utrecht: KNMG; 2002.
4. Verwijnen GM, Pollemans MC, Wijnen WHFW. Voortgangstoetsing. In: Metz JCM, Scherpbier AJJA, Vleuten CPM van der, editors. Medisch onderwijs in de praktijk. Assen: Koninklijke Van Gorcum b.v.; 1995.

\section{De auteurs:}

Mw. prof. dr. B. Meyboom-de Jong is emeritus hoogleraar Huisartsgeneeskunde, Groningen. Zij trad tevens op als voorzitter van de visitatiecommissie.

Prof. dr. J.C.M. Metz is emiritus hoogleraar Ontwikkeling en onderzoek van medisch onderwijs te Nijmegen en lid van de visitatiecommissie.

\section{Correspondentieadres:}

Mw. prof.dr. B. Meyboom-de Jong, Noorderhaven 6, 9712 VK Groningen, tel.: 050-3127523, b.meyboom@med. umcg.nl.

Belangenconflict: geen gemeld.

Financiële ondersteuning: geen gemeld.

\section{Summary}

In 2005 the quality of medical instruction and family practice training at the six Flemish universities that offer medical training was evaluated, using a site visit procedure similar to that used in the Netherlands. The resulting report is available at http://www.vlir.be/vlir/02thema\%27s/03kz/0303tweede-ronde.htm.

With six million inhabitants Flanders has four institutions offering full medical training while two, at Kortrijk and Hasselt, offer Bachelor degrees. The institutions and faculties vary much with respect to size, facilities, and teaching climate. The visiting committee's summary conclusion was that today's medical education in Flanders is of high quality and meets stipulated requirements, in part because of the many improvements implemented following the previous site visit in 1997.

Although Flanders has embraced the Bachelor/Master approach, training in medicine still takes seven years. Contrary to the situation in the Netherlands, the transition from undergraduate medical education to postgraduate (specialist) training programs in Flanders is seamless.

Creation of a combined physician/researcher $(M D / P h D)$ training program for talented and motivated students is recommended.

While Information Technology was quite advanced, study material was often still based on instructor-assembled and ready-made binders. The switch from an 'authority based' to an 'evidence based' curriculum should be implemented more systematically. To this end the power and effectiveness of education committees should be enhanced at the expense of individual teachers' autonomy.

Several interesting initiatives and successful projects in the area of medical education were noted, yet few have resulted in journal publications.

The visiting committee recommends that the "Maastricht progress test" be administered for some years to verify whether end goals are being achieved. (Meyboom-de Jong B, Metz. JCM. The quality of medical education at Flemish universities: findings of the site visit in 2005. Dutch Journal of Medical Education 2006;25(3):111-116) 